\title{
«SCORE-CoV-2» y su relación con el comportamiento del PIB
}

\section{"SCORE-CoV-2» and its relation to GDP performance}
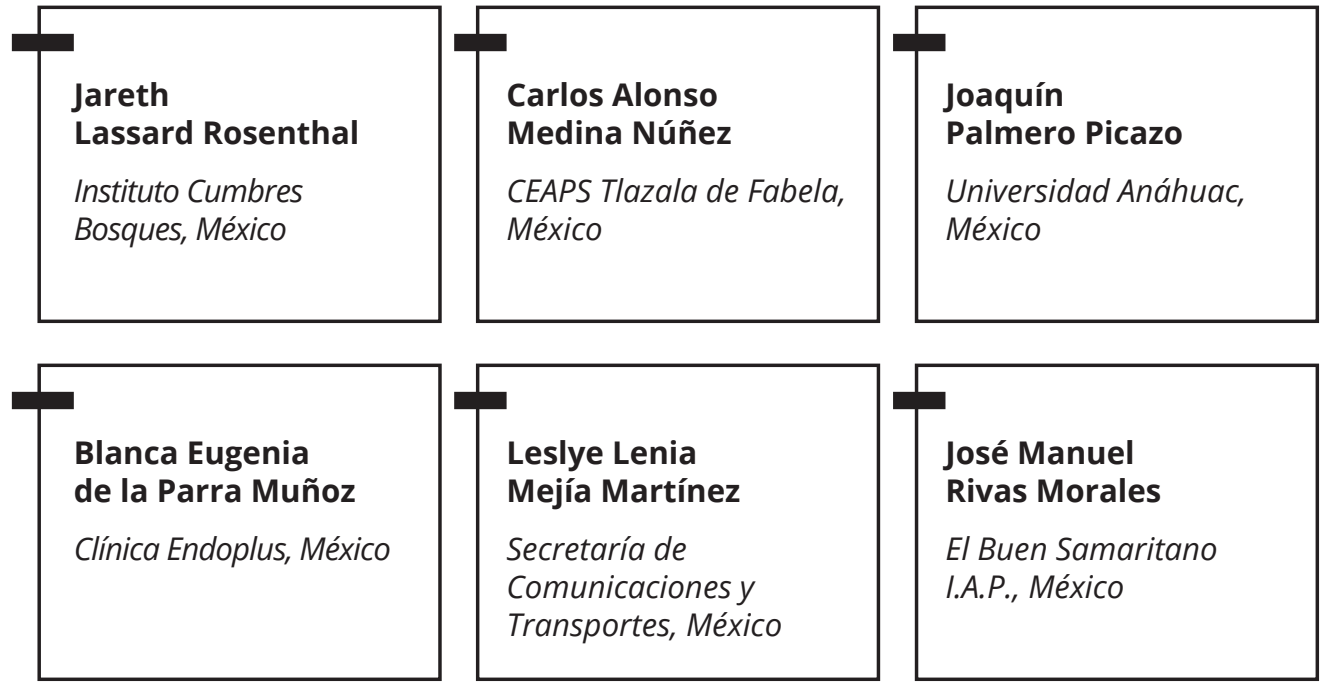

Recibido: 17 de abril de 2021.

Aprobado: 20 de mayo de 2021. 


\section{Resumen}

En el contexto global, que se ha visto afectado por el virus denominado SARS-CoV-2, cada país tuvo una forma específica de gestión de su población, por lo que se propone un sistema de evaluación (denominado "SCORE-CoV-2»), el cual pretende sintetizar las acciones y resultados de los países para afrontar la pandemia, tomando en cuenta ocho variables. La pandemia por COVID-19 ha dado un golpe a la economía mundial. Cifras del Banco Mundial esperan una contracción global de $5.2 \%$ del producto interno bruto (PIB) en 2020, presionando a millones hacia una situación de pobreza extrema. La hipótesis plantea que el valor SCORE-CoV-2 tendrá relación significativa con el comportamiento del PIB de los países, al ser un predictor de certeza sobre la evolución de las economías nacionales. Tras realizar el análisis estadístico respectivo, se obtuvo por medio de correlación de Pearson $\left(R^{2}<0.001\right)$ una falta de correlación entre el sistema de puntuación y el valor del PIB por país, pero fue posible analizar los puntos en los cuales cada país tiene una puntuación baja y, de esta manera, proponer nuevos manejos específicos para reducir el déficit de cada nación en relación con la COVID-19.

Palabras clave: COVID-19, puntuación, pandemia, PIB.

Clasificación JEL: C40.

\section{Abstract}

In the global context, which has been affected by the virus SARS-CoV-2, each country had a specific way of managing its population, so an evaluation system is proposed (named "SCORE-CoV-2»), which aims to synthesize the actions and results of the countries to face the pandemic, taking into account eight variables. The COVID-19 pandemic has dealt a blow to the world economy; World Bank figures expect a global contraction of $5.2 \%$ of gross domestic product (GDP) in 2020, pushing millions into extreme poverty. The hypothesis proposes that the SCORE-COV-2 value will have a significant relationship with the behavior of the countries' GDP, being a predictor of certainty about the evolution of the countries' economies. After performing the respective statistical analysis, the Pearson correlation $(R 2<0.001)$ showed a lack of relationship between the scoring system and the GDP value per country, but it was possible to analyze the points in which each country has a low score, and thus propose new specific management of each nation's deficit in COVID-19 issues.

Key Words: COVID-19, score, pandemic, GDP. JEL Classification: C40. 


\section{Introducción}

En el contexto global, que se ha visto afectado por el virus denominado SARS-CoV-2 (causante de la enfermedad COVID-19), cada país tuvo una forma específica de gestión de su población (Açikgöz y Günay, 2020). Dado que llevamos más de un año con esta problemática global (y a un año de que fuera declarada la pandemia, el 11 de marzo de 2020), es pertinente analizar a profundidad si las medidas de control de la enfermedad, medidas de prevención, canales de comunicación, logística del análisis estadístico, gestión de la vacunación, entre otros factores determinantes de esta pandemia, fueron llevados a cabo de manera eficiente.

Hemos centrando este estudio estadístico en México (Nicola et al., 2020), si bien, los países analizados en el presente trabajo son México, Brasil y Rusia, dado que tienen indicadores similares del producto interno bruto (PIB), según datos del Banco Mundial (2020), y PIB per cápita (PPA), según información del Fondo Monetario Internacional (2021), en la cual ninguno de los tres países tiene una separación de tres o más posiciones en los ranking entre sí y, además, liberan constantemente información actualizada para su análisis (Khan et al., 2020).

Para efectuar lo anterior, se propone un sistema de evaluación (denominada «SCORECoV-2»), que busca sintetizar las acciones y resultados de los países para afrontar la pandemia y así mostrarla con una puntuación accesible que va del 0 (el país con el peor manejo) al 100 (el país con el mejor manejo) (Açikgöz y Günay, 2020). Esta puntuación se hará con base en ocho variables: 1. Casos totales por millón de habitantes, 2. Muertes totales por millón de habitantes, 3. Mortalidad (en porcentaje), 4. Hospitalizaciones por millón de habitantes, 5. Pruebas totales por 1000 habitantes, 6. Vacunas por 100 habitantes, 7. El índice de rigor (creado por la Universidad de Oxford y el cual será explicado en la metodología) y 8. El exceso de mortalidad (en porcentaje) (Khan et al., 2020). Estas ocho variables pretenden presentar un contexto general del estado de la pandemia por cada país y a nivel global $y$, de esta manera, analizar en dónde se presentan áreas de mejoría. Se eligieron estas ocho variables debido a que todos los países a analizar en este estudio poseen datos e información de cada una de ellas, de modo que es posible realizar una comparación individualizada con la información existente (V'kovski et al., 2021). Este tipo de evaluación tiene como antecedente el estudio de Pardhan y Drydakis (2020), el cual encontró una correlación negativa significativa entre el número de casos de COVID-19 y el crecimiento del PIB en Europa en 2020. 
De este modo, para esta investigación se proponen los siguientes objetivos:

General: Valorar el uso del SCORE-CoV-2 para el manejo de la pandemia, así como otras funciones, tales como la predicción de la mejora del PIB de los países por medio de su puntuación.

Específico: Determinar las áreas de mejora en la pandemia por medio de la evaluación de cada variable de la SCORE-CoV-2 de México, Rusia y Brasil.

Y, dado que la hipótesis es que el sistema SCORE-CoV-2 tendrá una relación significativa con el comportamiento del PIB, al ser un predictor de certeza sobre la evolución de las economías de estos, hallará por lo tanto áreas de mejora para eficientar el crecimiento del PIB.

Este documento está estructurado como se explica a continuación. Primero, se presenta un marco teórico; posteriormente, la explicación metodológica de la obtención de la puntuación y el análisis estadístico realizado, para, por último, presentar por medio de diversas tablas y gráficas, entre las que se encuentran diagramas de caja y bigotes, los hallazgos obtenidos con este sistema y las tendencias a nivel mundial de sus puntuaciones. Adicionalmente, se presenta el análisis sobre la correlación hipotética entre el sistema y el PIB (Khan et al., 2020). Por último, se analiza, con apoyo de bibliografía, las puntuaciones obtenidas por México, Brasil y Rusia y el por qué del valor obtenido para, finalmente, llegar a una conclusión global del trabajo, otorgando un significado práctico a las puntuaciones obtenidas por estos países en cada rubro (Cavallo y Forman, 2020).

Se debe hacer hincapié en la importancia del desarrollo de un sistema unificado para la evaluación de múltiples variables, que por sí solas pueden dar una perspectiva general de un solo rubro de un hecho social tan importante como la pandemia ocasionada por el virus SARS-CoV-2 pero que, en conjunto, pueden ofrecer una evaluación de un panorama más amplio sobre los diferentes rubros que se abarcan y, de esta manera, evaluar las áreas de oportunidad en una emergencia como esta (V'kovski et al., 2021). Además, para la población es más sencillo interpretar un sistema de puntuación cuyos intervalos van del 0 y al 100, que la presencia de diferentes variables con diferentes interpretaciones (Cavallo y Forman, 2020), como por ejemplo los decesos sobre un millón de habitantes, la medición de la vacunación por cada 100 habitantes o índices que necesitan una revisión más extensa para su interpretación, como el índice de rigor (Nicola et al., 2020). 


\section{Marco teórico}

En diciembre de 2019, en la provincia de Hubei, China, se reportó una serie de casos que describía a pacientes ingresados a hospitalización con una nueva enfermedad caracterizada por neumonía e insuficiencia respiratoria aguda como consecuencia del nuevo coronavirus (SARS-CoV-2) (Islam e Iqbal, 2020). El 11 de febrero de 2020, la Organización Mundial de la Salud (OMS) denominó a este agente etiológico como COVID-19 (Ferrer, 2020).

Este virus causa una enfermedad sin tratamiento farmacológico específico, con mecanismos de transmisión que eran poco conocidos hasta fechas recientes, dificultando la implantación de intervenciones sanitarias por parte de los sistemas sanitarios (Setiati y Azwar, 2020), aunado a la diversidad de aspectos económicos, sociales, demográficos, así como la capacidad de los sistemas de salud para identificar y hacerle frente (Islam e Iqbal, 2020).

La evolución de esta pandemia ha sido muy heterogénea, con grandes diferencias entre países y regiones, incluso de un mismo país. Ello ha exigido comprender los factores que impulsan la velocidad de expansión, transmisibilidad, incidencia y mortalidad de la enfermedad (Aziz et al., 2020). La estructura y la capacidad de los sistemas sanitarios, así como los factores demográficos, son clave para el impacto de la pandemia (Medeiros de Figueiredo et al., 2020).

Se ha observado en estudios que los patrones esperados correspondientes a la evolución de una pandemia ocasionada por un virus infeccioso, con tasa de transmisibilidad rápida y alta letalidad en personas mayores y con comorbilidades, no son los típicos (Setiati y Azwar, 2020); la incidencia es una medida de frecuencia dependiente de las características del virus, la susceptibilidad, en cambio, se debe a las características de la población y los sistemas sanitarios (Medeiros de Figueiredo et al., 2020).

La letalidad es un indicador que depende de la capacidad de los países para identificar casos y muertes, fundamentales en un suceso epidemiológico (Islam e Iqbal, 2020). Se pueden justificar en caso de diferencias demográficas, factores socioeconómicos, ambientales o acceso a los sistemas de salud (Medeiros de Figueiredo et al., 2020).

El objetivo de las medidas de contención implementadas para mitigar la transmisión de la COVID-19 es impedir el colapso sanitario, evitando sobrepasar las capacidades 
de las instituciones, poniendo énfasis en los grupos de riesgo, personal sanitario y personas mayores, que se ha demostrado que son los más vulnerables. La OMS prevé que se contagiará de $40 \%$ a $60 \%$ de la población mundial (Islam e Iqbal, 2020). Ante esta situación, todos los gobiernos se verán sobrepasados, pues ningún sistema sanitario está preparado para lidiar con una situación así, por lo que acatar las medidas y recomendaciones impuestas es fundamental para tratar de frenar la curva de contagio (Rothan y Byrareddy, 2020).

La pandemia de COVID-19 ha dado un golpe a la economía mundial. El impacto económico y sanitario real aún es desconocido. Cifras del Banco Mundial reportadas en junio estiman una contracción global de $5.2 \%$ del PIB en 2020, presionando a millones hacia una situación de pobreza extrema (Setiati y Azwar, 2020). Las medidas de contención impuestas, las restricciones, el confinamiento generalizado, el cierre de escuelas, los trabajos no esenciales y las restricciones de tránsito nacional e internacional, la pérdida de empleos y todo esto aunado a la carga sanitaria repercute directamente en las economías. Por ello, todos los continentes y la mayoría de los países se vio en la necesidad de implementar estas disposiciones en menor o mayor medida (Li et al., 2020).

Los efectos de la crisis han sido más visibles en países emergentes, cuyas economías se basan, en gran proporción, en el turismo, el comercio internacional y la exportación de productos nacionales (Banco Mundial, 2020). Estos se vieron sumamente afectados por la crisis debido a los altos índices de personas en la economía informal, la urbanización desmesurada, la pobreza, la desigualdad, la fragilidad de los sistemas sanitarios y la vulnerabilidad de la población, que está en una situación más precaria que en países más desarrollados (Cepal-OPS, 2020).

Las medidas de contención y restricciones extremas no pueden sostenerse a largo plazo en la espera de un tratamiento o vacuna, en cambio, se busca reducir la incidencia y mitigar la transmisión. Cómo y cuándo un país disminuye estas restricciones es un gran reto para los gobiernos a nivel mundial, que buscan un equilibrio entre la salud y la economía (Han et al., 2020).

La OMS advirtió que la apertura prematura podía hacer resurgir o aumentar las infecciones, ocasionando un daño económico más severo a largo plazo. El levantamiento de las disposiciones de contención depende en gran medida de los factores siguientes: el estado de transmisión (calculado mediante indicadores de monitoreo de vigilancia epidemiológica); el compromiso de la comunidad (políticas de seguridad, utilización de barreras, medidas de seguridad en espacios públicos, comunicación 
eficaz de las autoridades, protección de los grupos de riesgo, apoyo económico); la capacidad de la salud pública (pruebas, rastreo y aislamiento [Setiati y Azwar, 2020], y el desempeño de las autoridades competentes); la capacidad de los sistemas sanitarios (equipo e insumos médicos, recursos humanos sanitarios e instituciones sanitarias suficientes) y las medidas de tránsito (restricciones de viaje) (Han et al., 2020).

Cada país cuenta con distintos indicadores a tomar en cuenta para evaluar el desempeño general respecto a la pandemia de COVID-19, donde idealmente se adoptan decisiones y formulan políticas públicas tomando en consideración la combinación de vigilancia y estado epidemiológico, así como las consecuencias sociales y económicas de las medidas de contención (Aziz et al., 2020). La transparencia de los objetivos del gobierno en la toma de decisiones y las medidas de su estrategia son fundamentales, pero no siempre ocurre de esa manera (Han et al., 2020).

El conocimiento del estado actual de la transmisión es fundamental para valorar la reapertura económica; la correcta vigilancia epidemiológica con un sistema e indicadores de calidad y la confirmación de que la cantidad de infecciones no ha sobrepasado los sistemas son cuestiones necesarias para comenzar a abrir paulatinamente las actividades económicas (Han et al., 2020).

Las comunidades tienen un rol fundamental en el manejo de la pandemia, para equilibrar la protección frente al virus y las implicaciones de la contracción económica (Setiati y Azwar, 2020). Las autoridades deberán buscar el empoderamiento de la sociedad mediante el acceso a la información para generar la confianza y las actitudes proactivas de la gente (Han et al., 2020).

Existe una falta de consenso internacional acerca del uso de mascarilla, el distanciamiento social y las medidas de higiene, a pesar de haber sido declaradas como una recomendación basada en evidencia por organizaciones como el Centro de Control y Prevención de Enfermedades (Centers for Disease Control and Prevention, 2021) y la OMS (2020), en cuyos textos se refleja una combinación de normas culturales, con mayor aceptación en ciertos países. No obstante, se ha demostrado que es fundamental su uso para mitigar la transmisión y disminuir la incidencia (Aziz et al., 2020). Respecto a esta medida, ciertos gobiernos han acatado la recomendación de obligatoriedad y para otros la mascarilla sigue siendo un artículo de protección opcional (Han et al., 2020).

Las políticas de salud pública que propongan y realicen una vigilancia que incluya la búsqueda de casos activos, confirmados, sospechosos y contactos expuestos, la extensa aplicación de pruebas de detección y el aislamiento oportuno son el centro de 
toda estrategia para lograr un buen desempeño frente a la crisis sanitaria (Setiati y Azwar, 2020). Al inicio de la pandemia, muchos países reservaban las pruebas de detección para los casos sintomáticos. Esto ha evolucionado gracias a la evidencia científica; cada vez más países buscan la aplicación masiva de este método, aun si en ciertos gobiernos esto sigue siendo deficiente (Han et al., 2020).

La capacidad de los sistemas de salud es un factor crucial a escala global para hacer frente a posibles aumentos en la tasa de incidencia una vez que las medidas de contención se levanten (Setiati y Azwar, 2020); esto incluye tener suficientes instituciones, capacidad hospitalaria, insumos, espacio en áreas de cuidados intensivos, equipo médico y recursos humanos del sector sanitario. Todos estos factores son de gran importancia para el correcto manejo de la pandemia. Un fallo en la inversión o adquisición de recursos y no tener capacidad suficiente pueden ser factores catastróficos (Han et al., 2020).

No se espera que la pandemia concluya hasta que exista un despliegue global de vacunas que ofrezcan protección para casos de infección severa y se logre así la inmunización de rebaño (Setiati y Azwar, 2020). Múltiples agencias de países alrededor del mundo han aprobado el uso de las vacunas en humanos, a partir de 2021, aunque esta autorización no es suficiente para alcanzar un control global de la COVID-19. La producción masiva de vacuna, los accesibilidad de los costos, la asignación y distribución global, son factores decisivos para alcanzar un control a futuro (Wouters et al., 2021).

Las vacunas son un factor primordial para el funcionamiento de la sociedad. Su desarrollo, sin embargo, no tendrá significado para las personas que no pueden vacunarse de manera oportuna (Li et al., 2020). Para cumplir el objetivo de control global se requiere que las vacunas sean asequibles y estén disponibles para los países, y que los gobiernos tengan la capacidad y la política de distribuirlas localmente (Wouters et al., 2021).

Los países en que la proporción del PIB destinada a la salud es insuficiente y la sociedad tiene que gastar de su bolsillo para acceder a los sistemas sanitarios pone en situación de vulnerabilidad a la sociedad (Aziz et al., 2020). Eso es así sobre todo en aquellos en que las características demográficas incluyen, entre otras, una carga de comorbilidad importante, población añosa, hacinamiento en viviendas, desigualdad, desnutrición, falta de higiene o acceso a los servicios básicos. Todos estos se vuelven factores de riesgo importantes para el desarrollo de infección severa por COVID-19, aumentando la carga y el gasto económico en materia de salud (Cepal-OPS, 2020). 


\section{Metodología}

Se obtuvo información de la base de datos Our World in Data, creada por la Universidad de Oxford (Our World in Data, 2021). Esta plataforma obtiene los datos oficiales de cada país, y sintetiza la información de manera que sea comparable una con otra. Tras una depuración de las 74474 entradas de información, y de sus 59 respectivas variables, se clasificaron los datos en tres momentos de corte (al inicio de la pandemia y cada 6 meses, hasta llegar a marzo de 2021): 1. ${ }^{\circ}$ de marzo de $2020,1 .^{\circ}$ de septiembre de 2020 y $1 .^{\circ}$ de marzo de 2021 . A estos tres momentos se les asignaron sus respectivas variables, con ocho a evaluar: 1) total de casos por millón de habitantes; 2) total de muertes por millón de habitantes; 3) mortalidad (en porcentaje); 4) hospitalizaciones por millón de habitantes; 5) total de pruebas por 1000 habitantes; 6) vacunas por 100 habitantes; 7) el índice de rigor, y 8) exceso de mortalidad (en porcentaje).

El índice de rigor (o Stringency Index), es el resultado de una evaluación matemática creada por la Universidad de Oxford. Este evalúa el cierre de escuelas, el cierre de espacios de trabajo, la cancelación de eventos públicos, las restricciones de reuniones, el cierre del transporte público, el requerimiento de quedarse en casa, las restricciones del movimiento dentro del país, las restricciones del movimiento internacional y las campañas de información pública. La escala tiene una puntuación de 0 a 100 puntos, en donde el país más estricto es el que tiene la puntuación de 100 puntos. El valor se obtiene tras el procesamiento de los datos recopilados de más de 400 instituciones a nivel mundial, y su codificación determina por medio de software el valor final (Our World in Data, 2021).

En la evaluación de las ocho variables ya mencionadas, se realizó la puntuación de cada resultado, del 0 al 10, teniendo como puntuación máxima, al igual que el índice de rigor, el país con mejores resultados en cada variable. Con el conteo, se realizó una suma total de los puntos y, después, se ajustó la calificación de tal forma que la puntuación máxima del SCORE-CoV-2 fuese de 100 puntos.

Posteriormente, se repitió el proceso en los tres cortes para realizar la evaluación entre la diferencia del crecimiento de PIB anual porcentual entre el promedio de 2017-2018 y 2020 (es decir, dos años prepandémicos y uno pandémico, respectivamente) y la diferencia entre las puntuaciones del SCORE-CoV-2 de marzo de 2021 y marzo de 2020. El resultado se analizó por medio de la correlación de Pearson, 
usando la fórmula $\mathrm{R}=\frac{\Sigma(x-\underline{x})(y-\underline{y})}{\sqrt{\Sigma(x-\underline{x})^{2} \Sigma(y-\underline{y})^{2}}}$, donde «X» $\mathrm{e}$ «y» son las medias de las muestras del SCORE-CoV-2 y el PIB para evaluar la relevancia del uso del SCORE-CoV-2 como un instrumento predictivo de la contracción o crecimiento del PIB por país. El uso de la correlación de Pearson se debe a la presencia de dos variables cuantitativas y la exactitud que ofrece con grandes bases de datos, como la evaluada en este artículo y con fundamento en lo realizado por otros autores (Pardhan y Drydakis, 2020).

Se realizó una evaluación de los países en sus tres puntos de corte, calculando media aritmética, desviación estándar, varianza, mediana y los tres cuartiles, para evaluar el movimiento internacional respecto a nuestro sistema de puntuación y valorar su aumento o disminución a lo largo del año evaluado. Por último, se evaluó de manera visual empleando una caja de bigotes, para así observar el posicionamiento global en el sistema de puntuación.

Finalmente, se realizó una evaluación de los tres países mencionados (México, Brasil y Rusia) con sus tres momentos de corte, la diferencia entre los dos cortes de marzo, y su diferencial del PIB, evaluando la predicción del PIB por medio de la puntuación con la correlación de Pearson. Además, se observó el comportamiento del SCORE-CoV-2 en las tres naciones a lo largo del tiempo, para finalmente buscar de manera puntual las variables con menor puntuación de cada país y, de esta manera, encontrar las áreas de mejora de cada país. Estas, a su vez, se sustentan con la bibliografía especializada en temas socio-político-económicos.

\section{Resultados}

Tras la obtención y depuración de la base de datos, se efectuó la puntuación tal como se menciona en la sección de la metodología. En la tabla 1 se encuentra un ejemplo, de México en el corte del 1 de marzo de 2021, donde se puede observar la puntuación de 8.850 de 10 puntos posibles en casos totales, 3.37 de 10 puntos en muertes totales, 6.753 de 10 puntos en porcentaje de mortalidad, 5 puntos en hospitalizaciones, y 0.11 y 0.267 de 10 posibles cada uno en pruebas y vacunación, respectivamente; esto sumado a la puntuación del índice de rigor y al exceso de mortalidad y, posteriormente, basándose en los 100 puntos que otorga la puntuación del SCORE-CoV-2 para México en ese corte (ver tabla 1). 
Tabla 1. SCORE-CoV-2 de México de $1 .^{\circ}$ de marzo de 2021

\begin{tabular}{|l|c|c|}
\hline & Valor & Puntuación \\
\hline 1) Casos totales por millón de habitantes & 16204 & 8.850 \\
\hline 2) Muertes totales por millón de habitantes & 1443 & 3.37 \\
\hline 3) Mortalidad (porcentaje) & 8 & 6.753 \\
\hline 4) Hospitalizaciones por millón de habitantes & 15583 & 5.000 \\
\hline 5) Pruebas totales por 1000 habitantes & 39 & 0.116 \\
\hline 6) Vacunación por cada 100 habitantes & 1 & 0.267 \\
\hline 7) Índice de rigor & 60 & 6.550 \\
\hline 8) Exceso de mortalidad (porcentaje) & 67 & 2.310 \\
\hline Diferencia promedio PIB 2017-2018 a 2020 (porcentaje) & N/A & -8.9 \\
\hline Puntuación total (base 80) & N/A & 33.22 \\
\hline Puntuación total (base 100) & N/A & $\mathbf{4 2}$ \\
\hline
\end{tabular}

Fuentes: Our World in Data (2021) y Banco Mundial (2020).

De esta manera, se recopiló la información de todos los países en los cortes $1 .^{\circ}$ de marzo de 2020, $1 .^{\circ}$ de septiembre de 2020 y $1 .^{\circ}$ de marzo de 2021, y se efectuó la asignación de puntos. En las gráficas 1, 2 y 3 se encuentra la distribución mundial de puntuaciones en cada punto de corte. Como se puede observar en estas gráficas, el intervalo con la moda a lo largo de los cortes fue disminuyendo su valor, suponiendo una disminución de las puntuaciones más frecuentes y, por ende, una regresión a nivel internacional de esta puntuación, siendo una de las posibles causas la falta de un consenso internacional de las diferentes medidas a acatar en la pandemia (Centers for Disease Control and Prevention, 2021; OMS, 2020). (Ver gráfica 1 , gráfica 2 y gráfica 3 ). 
Gráfica 1. Distribución mundial del SCORE-CoV-2 en el corte de $1 .^{\circ}$ de marzo de 2020

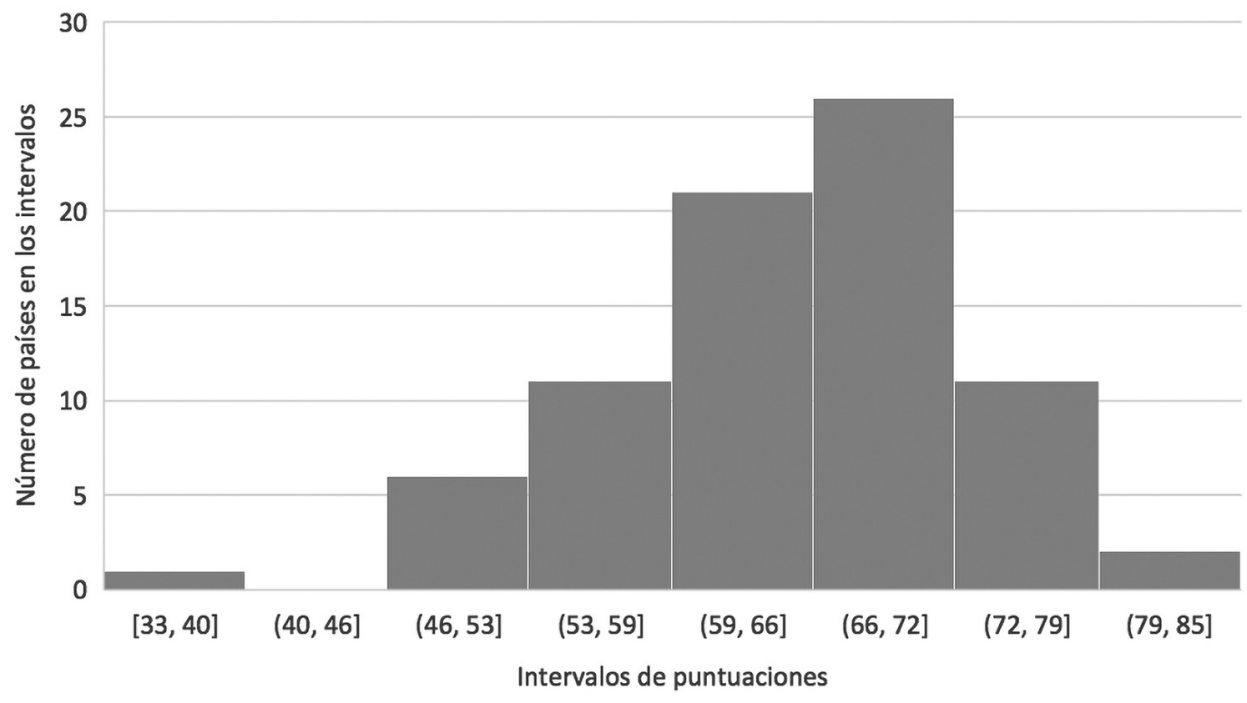

Fuente: elaboración propia.

Gráfica 2. Distribución mundial del SCORE-CoV-2 en el corte de $1 .^{\circ}$ de septiembre de 2020

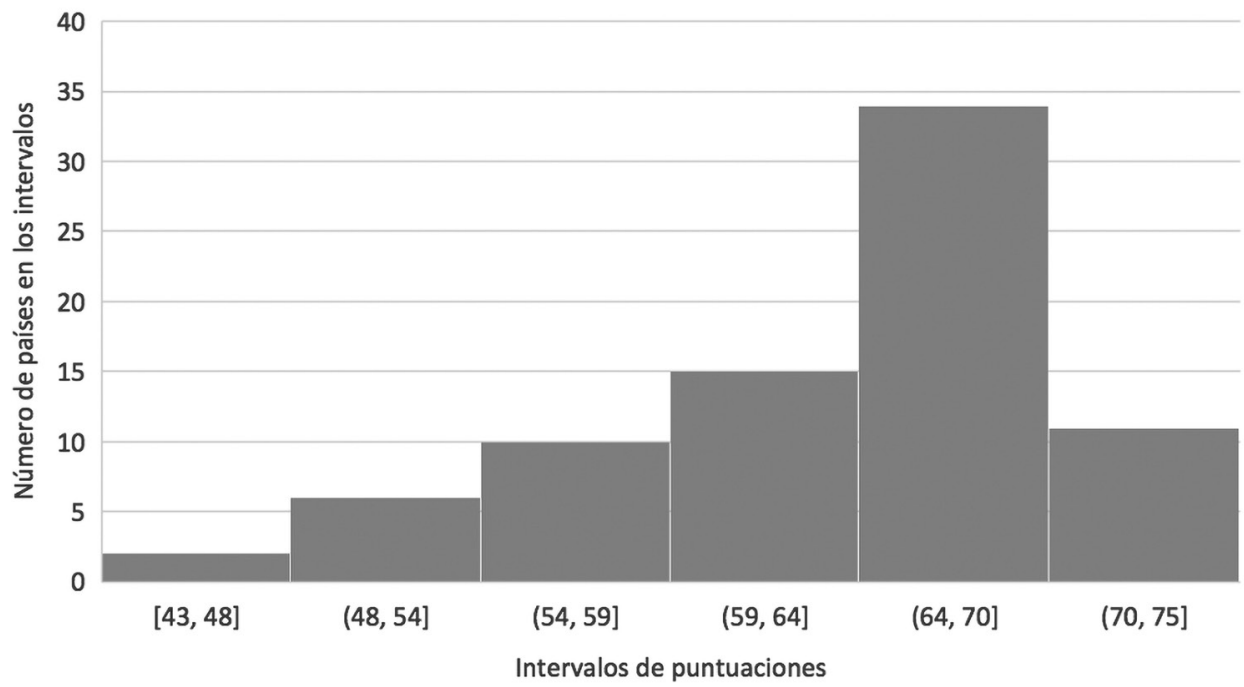

Fuente: elaboración propia. 
Gráfica 3. Distribución mundial del SCORE-CoV-2 en el corte de 1. ${ }^{\circ}$ de marzo de 2021

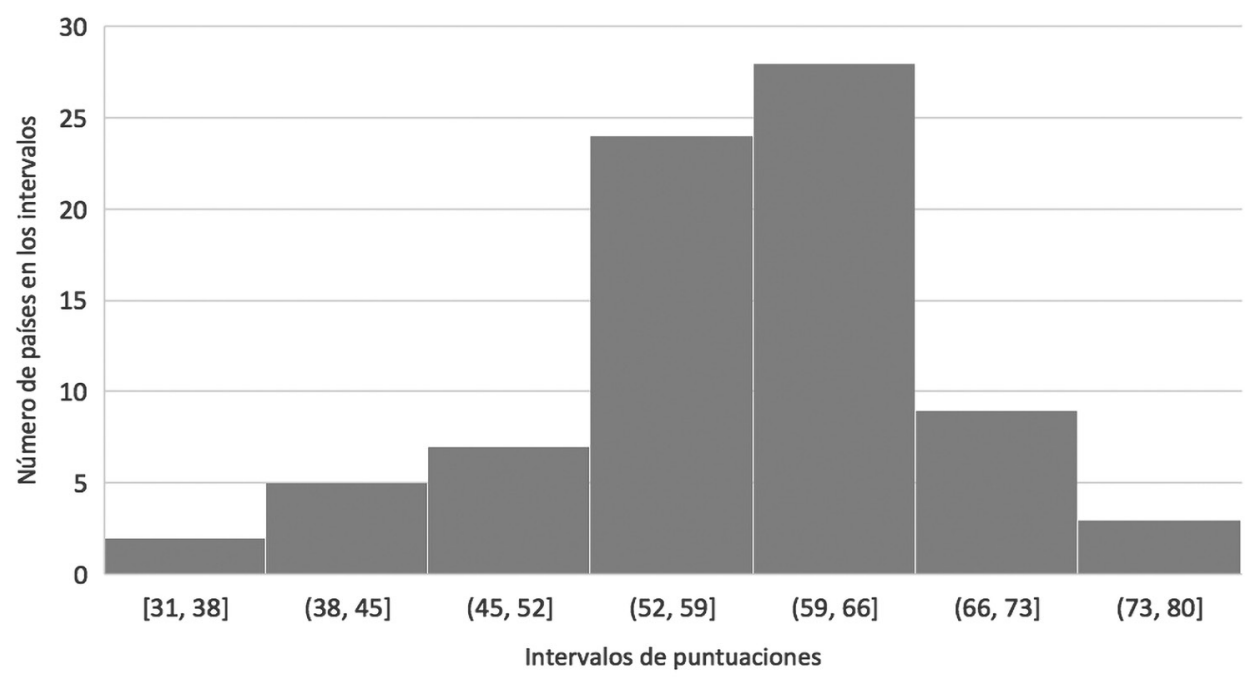

Fuente: elaboración propia.

Tal y como se observa en las gráficas 1, 2 y 3, la tendencia de los países parece dirigirse hacia la disminución de la puntuación, lo cual se confirma en el diagrama de caja con bigotes, en la gráfica 4 . Adicionalmente, con estos datos se obtuvieron las medidas de tendencia central, presentadas en la tabla 2. Con esta gráfica y tabla es posible observar que tanto el promedio como la mediana tienen una tendencia decreciente, por lo que se infiere que los países tienden al empeoramiento de sus medidas contra la COVID-19, y que $75 \%$ de las naciones se encuentra por debajo de los 70 puntos en el sistema de puntuación. Estos datos son de gran relevancia dado que, con el desglose de cada variable, pueden observarse las áreas de mejora, lo cual se analizará posteriormente (Zhao et al., 2020). (Ver gráfica 4 y tabla 2). 
Gráfica 4. Diagrama de cajas y bigotes de los tres cortes

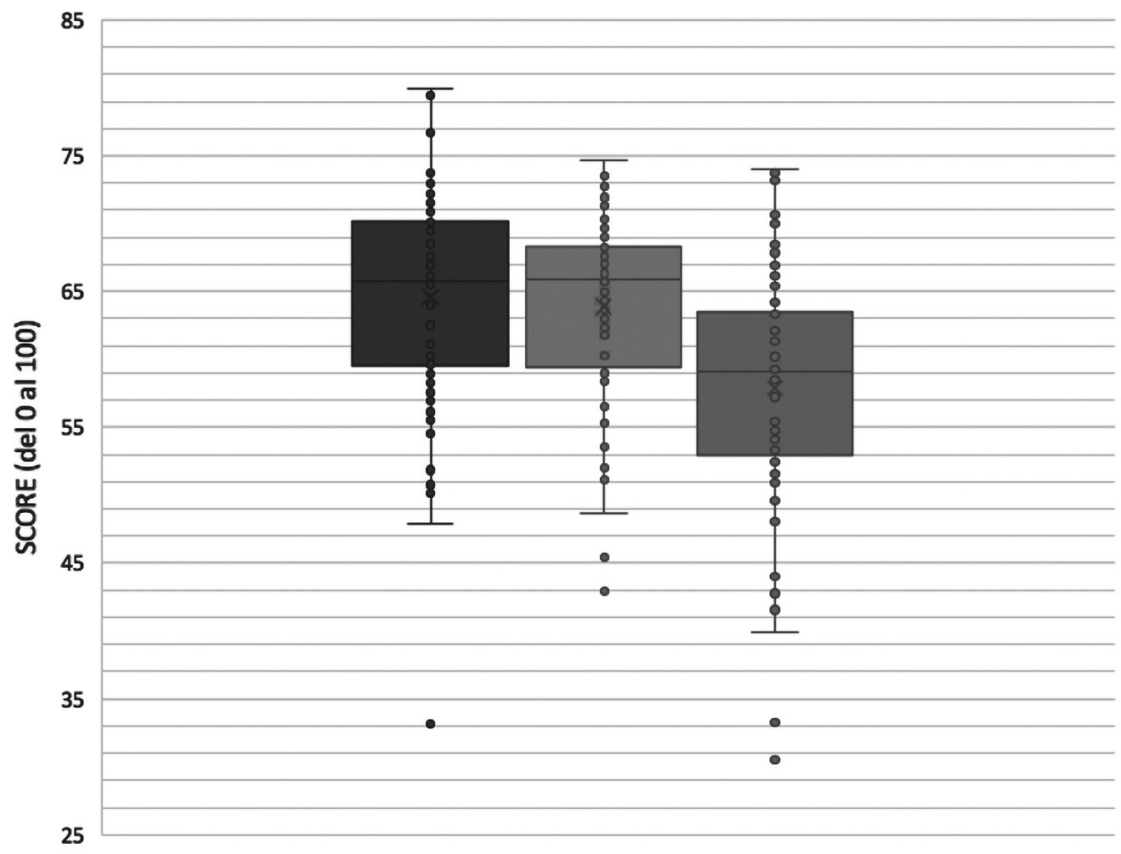

PUNTUACIÓN $01 / 03 / 2020$

PUNTUACIÓN 01/09/2020

PUNTUACIÓN 01/03/2021

Fuente: elaboración propia.

Tabla 2. Medidas de tendencia en cada corte con el SCORE-CoV-2

\begin{tabular}{|c|c|c|c|}
\hline & $\begin{array}{l}\text { Corte del } 1 .^{\circ} \text { de } \\
\text { marzo de } 2020\end{array}$ & $\begin{array}{c}\text { Corte del } 1 .^{\circ} \text { de } \\
\text { septiembre de } 2020\end{array}$ & $\begin{array}{l}\text { Corte del } 1 .^{\circ} \text { de } \\
\text { marzo de } 2021\end{array}$ \\
\hline Media & 64.551 & 63.851 & 57.871 \\
\hline Desviación estándar & 7.910 & 6.588 & 8.563 \\
\hline Varianza & 62.562 & 43.405 & 73.322 \\
\hline Cuartil 1 (Q1) & 59.555 & 59.471 & 52.925 \\
\hline Cuartil 2 (Q2) & 65.736 & 65.876 & 59.100 \\
\hline Cuartil 3 (Q3) & 70.205 & 68.305 & 63.525 \\
\hline
\end{tabular}

Fuente: elaboración propia. 
Ahora bien, con estos datos se realizó la evaluación estadística por medio de la correlación de Pearson, para determinar si la relación entre la diferencia del PIB del promedio de 2017-2018 y 2020, y su puntuación es significativa y así inferir, mediante una función matemática, el futuro socioeconómico de los países conforme a su puntuación. En la gráfica 5 se observa una correlación de Pearson de 0.0006, por lo cual se rechaza la hipótesis propuesta acerca de esta correlación, de modo que datos como los mencionados por la Cepal no pueden valorarse por medio de este sistema (Cepal-OPS, 2020). (Ver gráfica 5).

Gráfica 5. Correlación del PIB con el SCORE-CoV-2 por medio de la correlación de Pearson

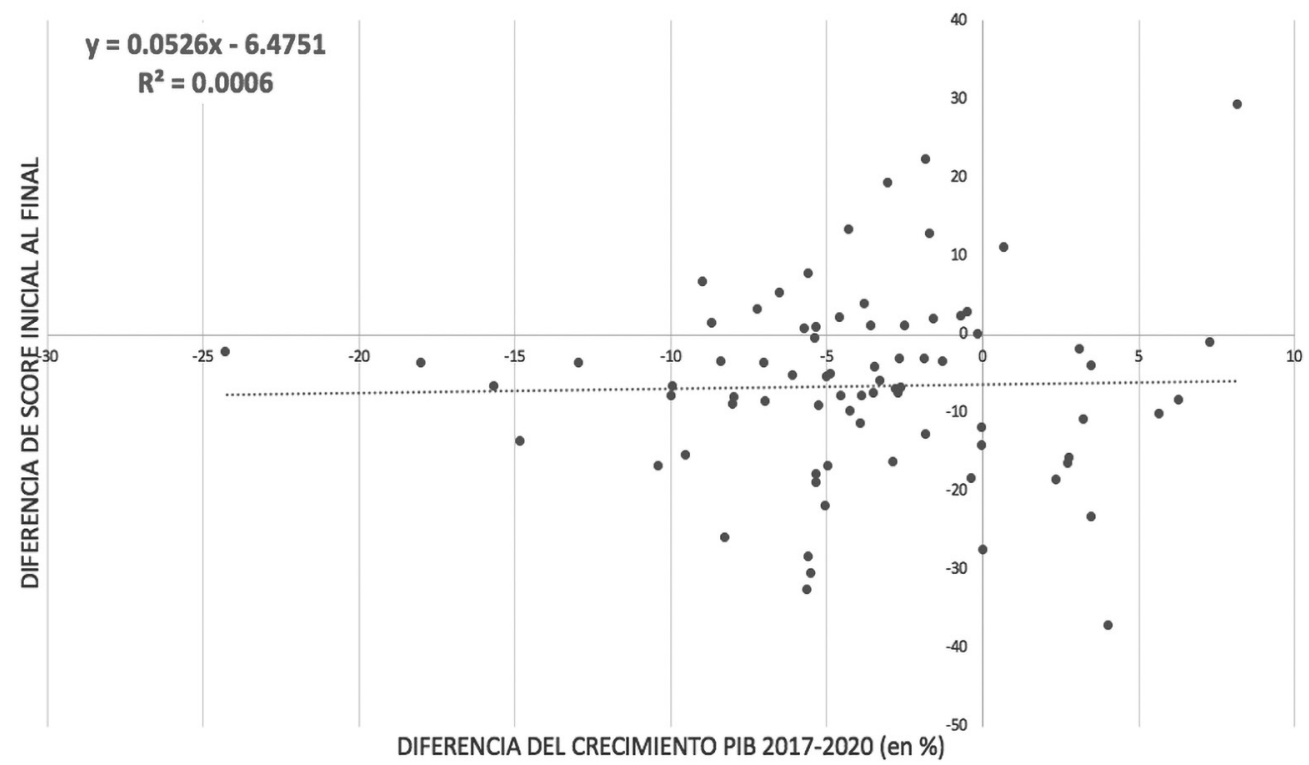

Fuente: elaboración propia.

Finalmente, se realizó la comparación de los tres países mencionados anteriormente: México, Rusia y Brasil, y se elaboró la tabla 3, en la cual puede observarse el puntaje con tendencia negativa de los tres países. Esto puede apreciarse gráficamente en la gráfica 6. (Ver la tabla 3 y la gráfica 6). 
Tabla 3. Comparación entre Brasil, México y Rusia

\begin{tabular}{|c|c|c|c|c|}
\hline País & $\begin{array}{c}\text { Corte del 1. }^{\circ} \\
\text { de marzo } \\
\text { de } \mathbf{2 0 2 0}\end{array}$ & $\begin{array}{c}\text { Corte del 1. }^{\circ} \\
\text { de septiembre } \\
\text { de 2020 }\end{array}$ & $\begin{array}{c}\text { Corte del 1. }^{\circ} \\
\text { de marzo } \\
\text { de 2021 }\end{array}$ & $\begin{array}{c}\text { Diferencia de }_{\text {puntaje final }} \\
\text { e inicial }\end{array}$ \\
\hline Brasil & 73 & 59 & 40 & -33 \\
\hline México & 68 & 49 & 42 & -26 \\
\hline Rusia & 63 & 66 & 55 & -8 \\
\hline
\end{tabular}

Fuente: elaboración propia.

Gráfica 6. Puntuaciones de México, Brasil y Rusia por medio del SCORE-CoV-2

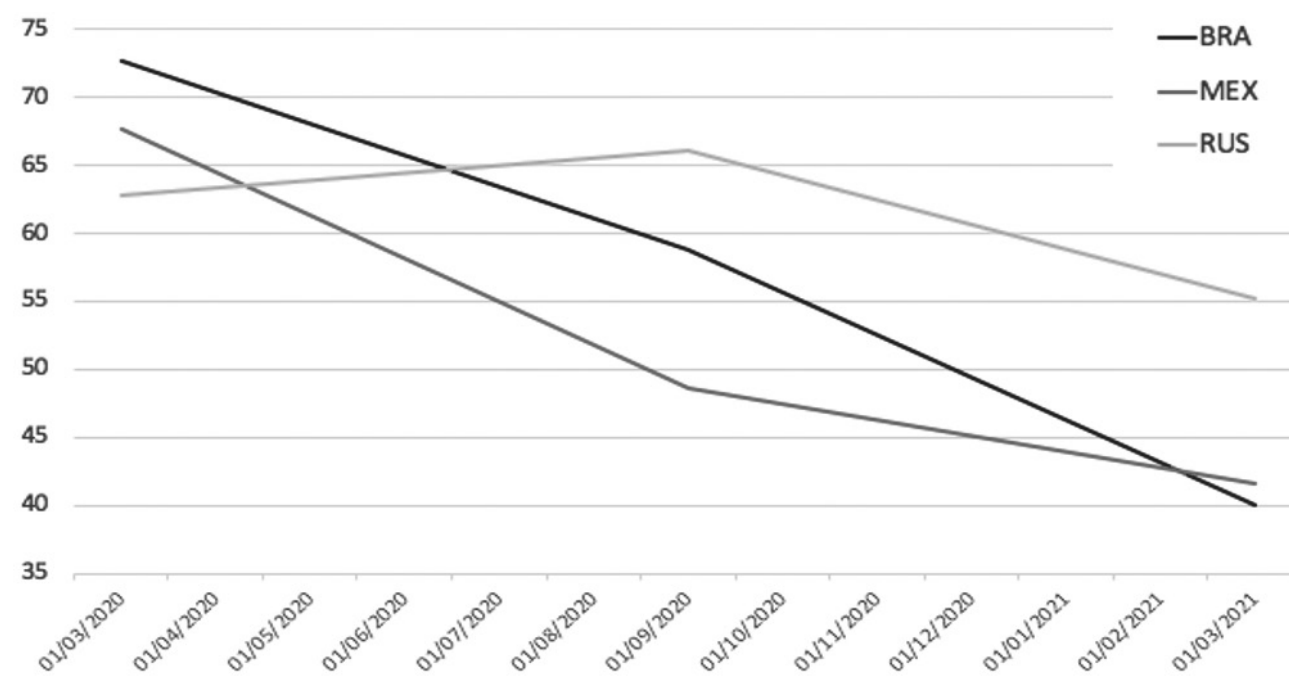

Fuente: elaboración propia.

De esta forma, es posible analizar cada país con sus respectivos puntajes y observar las áreas de mejora en estos por medio de la separación de cada una de sus variables.

Las puntuaciones obtenidas por México descienden durante los tres cortes de puntaje. En el primer corte, obtiene 68 puntos, y una de las causas de ello corresponde a las decisiones del gobierno del presidente Andrés Manuel López Obrador, que rechazó el uso obligatorio de cubrebocas, el fomento de actividades que iban en 
contra del distanciamiento físico y el déficit en las pruebas realizadas para la detección del virus (Ibarra et al., 2020). En el corte de septiembre de 2020, obtiene 49 puntos, ya que en ese momento se contaban 648171 contagiados y ocupaba el cuarto lugar entre los países a nivel mundial en número de muertes, así como primer lugar en muertes de personal de salud; en cuanto a cifras de hospitalizaciones, los datos eran los siguientes: hospitalización general, 11074 (35\% de ocupación a nivel nacional) y camas con ventilador, 3275 (31 \% de ocupación) (Gobierno de México, Secretaría de Salud, 2021). Ello presenta semejanza con lo comentado por Han y colaboradores (Han et al., 2020).

Al corte de marzo de 2021, se registró un total de 2283465 casos estimados, 1639943 personas recuperadas y 186152 defunciones confirmadas. Asimismo, se han recibido 3839625 dosis de vacunas contra el virus SARS-CoV-2 (Gobierno de México, Secretaría de Salud, 2021).

El índice de rigor se alimenta de las políticas públicas vigentes, tales como capacitaciones gratuitas para la población en cursos como los siguientes: Todo sobre la prevención del COVID-19; Plan de acción para el hogar ante el COVID-19; Cuidado de personas adultas mayores ante el COVID-19; Cuidado de la salud mental en situaciones de emergencia; Recomendaciones para un retorno saludable al trabajo ante COVID-19 (Gobierno de México, 2021).

De acuerdo con las cifras del Sistema de Información de la Red IRAG, desarrollado por el Laboratorio Internacional de Tecnología e Investigación Espacial (iSTAR Lab) del Instituto de Geografía de la UNAM (Ibarra et al., 2020), para la Secretaría de Salud, la ocupación de camas de hospital ha disminuido en el país, debido a que en todos los estados de la República, con excepción de la Ciudad de México, se registra una ocupación menor al 50 \% de la capacidad de camas (Secretaría de Salud, Sistema de Información de la Red IRAG, s/f).

En el caso de Brasil, puede observarse cómo sus puntajes disminuyeron a lo largo del año en los tres aspectos, lo que implica que el país se encuentra cada vez en una situación más delicada. El 1. ${ }^{\circ}$ de marzo de 2020, se calificó con 73 puntos, en ese momento se reportó el segundo caso confirmado de COVID-19; el 18 de ese mes se informó de la primera muerte por el mismo, pero el presidente Jair Bolsonaro acusó a todos de caer en «histeria» y puso énfasis en que no tomaría medidas en el asunto (Zhao et al., 2020). Para septiembre de 2020, obtuvieron 59 puntos, contaban con 3908272 casos, y 121381 fallecimientos, ubicándose entre los países más afectados, además de 89405 hospitalizaciones, de las cuales, 22.6 \% estaban 
en terapia intensiva. La campaña de vacunación de ese país empezó en diciembre de 2020, por lo que en los dos primeros cortes reciben mala calificación en ese rubro (Ribeiro et al., 2020). Para marzo de 2021, se encontraba en su peor momento, las unidades de cuidados intensivos funcionaban a más de $80 \%$ de su capacidad. El sistema de salud estaba en inminente peligro del colapso. Es evidente que las medidas tomadas por el gobierno fueron insuficientes, gran parte de las escuelas permanecieron abiertas (aunque con menor capacidad), el número de personas contagiadas ascendió a más de 11 millones y ocurrieron aproximadamente 128 muertes por cada 100000 habitantes (Ribeiro et al., 2020).

En el caso de Rusia, la calificación inicial fue de 63 puntos, que empeoró al llegar a 66; actualmente se encuentra en 55 puntos. En todos los casos ha sido una calificación desafortunada, sin embargo, la tendencia es hacia la mejora. Estos cambios se ven reflejados en las variaciones que se han presentado en las variables estudiadas durante los tres períodos concretos (Logunov et al., 2020). Por ejemplo, a inicios de marzo de 2020, se presentaron dos turistas chinos contagiados y el primer infectado ruso se registró el 2 de marzo del mismo año (UNAM, 2020). Derivado de ello, las medidas de rigor que siguió la nación se basaron en el cierre de las fronteras y el aislamiento de la población. También se comenzó la etapa de desarrollo farmacológico, proponiendo para finales de marzo de 2020 tres fármacos que pretendían atacar al virus que generó la pandemia: antiviral triazivirin, fosprenil y fortopren («Desarrolla Rusia...», 2020).

En el segundo corte, de septiembre de 2020, se superó el millón de contagios, debido a que hubo un incremento de 4729 casos en tan solo 24 horas, detectados en su mayoría en la capital, Moscú, y en San Petersburgo. Se presentaron cerca de 17299 defunciones y 815000 pacientes recuperados. Sin embargo, en la gráfica comparativa de puntuaciones de los tres países, se observa la desmejora de la calificación general de Rusia (Logunov et al., 2020). Uno de los factores principales que incrementó los casos de contagio fue la decisión gubernamental, a cargo de la Oficina Nacional de Protección al Consumidor, de reabrir los centros educativos, pues se consideró que las condiciones epidemiológicas permitirían el inicio del ciclo escolar presencial («Coronavirus en Rusia...», 2020).

En abril de 2020, la OMS recomendó a Rusia no celebrar el evento del desfile militar conmemorativo, debido al alto riesgo de propagación del virus. Sin embargo, el 24 de junio, se llevó a cabo el desfile militar del Día de la Victoria, presidido por Vladimir Putin, acompañado de varios jefes de Estado de distintos países. En esta celebración se buscó crear un sistema de seguridad global fiable para hacer frente a las 
amenazas del mundo actual. Ese día, Rusia superó los 600000 casos de COVID-19, después de registrar 7176 nuevos infectados en 24 horas (Logunov et al., 2020). Esto situó el total en 606881 . Además, se registraron 154 muertes, para llegar a 8513, y los recuperados superaban los 368000 («Coronavirus en Rusia...», 2020). El mismo mes, el desarrollo de las vacunas reflejaba un gran avance, debido a que comenzaron a realizarse pruebas en voluntarios con vacunas experimentales. El ejercicio de ensayo-error permitió un progreso más acelerado de la Sputnik V (Logunov et al., 2020).

En el tercer corte, Rusia superó los 4 millones de casos de COVID-19, según datos del Comité gubernamental para hacer frente a la pandemia de coronavirus. A mediados de febrero se habían detectado 4012770 casos positivos, que equivalían a 14494 contagios por día, el monto más bajo desde octubre de 2020 (Logunov et al., 2020). De acuerdo con el centro operativo de lucha contra el coronavirus, hasta el momento han fallecido 78234 personas a causa de la enfermedad de COVID-19. («Rusia superó los...», 2021).

En la revista científica The Lancet, en el artículo publicado por Logunov et al. (2020) se confirmó que la efectividad de la vacuna Sputnik V fue de $91.6 \%$ en un análisis intermedio de un ensayo fase III. Ello podría representar un incremento en el número de órdenes de vacunas solicitadas por terceros países, lo cual beneficiaría económicamente a la nación. Aunado a lo anterior, Rusia comenzó a aplicar la vacuna a principios de diciembre, pero aún no ha logrado alcanzar un ritmo que le permita vislumbrar el final de la campaña de inmunización.

\section{Conclusiones}

En este proyecto de investigación se llega a la conclusión de que el sistema de puntuación denominado SCORE-CoV-2 no tiene relación estadísticamente significativa con respecto al comportamiento del PIB como marcador económico. Esto se debe a que las variables incluidas en el estudio no tienen relevancia en su conjunto en un escenario macroeconómico, como es el impacto en el PIB de una nación en concreto (Delgado et al., 2020). Por lo tanto, se rechaza la hipótesis nula y se toma la hipótesis alterna. Asimismo, se deja abierta la posibilidad de un futuro análisis en el que se correrá de manera individualizada cada variable con respecto al PIB (Caicedo et al., 2020), estimándose que podría existir una relación directa con dicho marcador macroeconómico (Zhao et al., 2020). Esta falta de correlación puede 
deberse a que cada país tiene diferentes actividades económicas que impactan de mayor o menor medida el PIB, por lo que debe tenerse en cuenta cada área geográfica de manera individualizada para evaluarse con este sistema de puntuación, considerando metodologías como las usadas por otros autores (Pardhan y Drydakis, 2020).

Es claro que, en su mayoría, el comportamiento individualizado de los diferentes países no cumple con una puntuación satisfactoria, por lo que en cada uno se necesitan medidas individualizadas para un control óptimo de la pandemia. Los tres países que se tomaron en cuenta en la metodología, Rusia, Brasil y México, son naciones en vías de desarrollo, de acuerdo con la clasificación de la OMS; sus características demográficas y sociopolíticas son similares, y los gobiernos actuales de México y Brasil fueron de los pocos en el mundo que no impusieron restricciones, lo cual fue visible en un mal puntaje en el índice de rigor. Ello llevó a la contracción del PIB de estas naciones y a una situación de emergencia sanitaria (Rodriguez-Morales et al., 2020). Concluimos que la toma de medidas oportunas con respecto a la pandemia mejoró la situación individual de cada nación (Shrestha et al., 2020).

Por último, presentamos el análisis de los tres países (Brasil, México y Rusia). Como se puede apreciar en la tabla 4, las tres naciones que se comparan tendieron a modificar su puntuación de manera negativa con el paso del tiempo (ver tabla 4), en las tres fechas de corte:

- El país con peores medidas de implementación con finalidad de reducir la incidencia por casos de COVID-19 fue Brasil, con un promedio de 7.31. México fue el país con mejores medidas y programas sociales (Delgado et al., 2020).

- La nación con la peor gestión de insumos, disponibilidad hospitalaria y características poblacionales fue México, con un 6.42. El mejor país en este rubro fue Rusia (Andrus et al., 2020).

- De los tres países, el que tiene mayor deficiencia general en salud y características individualizadas del paciente fue Rusia, con un 6.42, y Brasil el mejor, con 9.34 (Ferreira et al., 2021).

- El mejor sistema de salud y gestión médica de estos tres países es Brasil, con 8.33, y Rusia, el peor, con 5.67 de promedio (Delgado et al., 2020).

- El mejor puntaje en la gestión y aplicación de pruebas como método de tamizaje fue de Rusia, con 5.24, y el peor, Brasil, con 1.66 (Andrus et al., 2020). 
- En el caso de la implementación de campañas de vacunación y aplicación de vacuna, el que tuvo mejor puntuación fue Brasil, con tan solo 0.54 puntos; le siguió Rusia, que aun siendo el único país de la lista en desarrollar una vacuna con autorización de aplicación, no es el mejor de estos tres, con tan solo 0.49 puntos (Ferreira et al., 2021).

- El que aplicó mejores medidas de distanciamiento social, cierre de escuelas, negocios, restricción de reuniones y cancelación de eventos públicos fue México, con 4.76. Tomando en cuenta esto, podemos concluir que la estrategia del «Semáforo epidemiológico» tiene un funcionamiento adecuado para la apertura de actividades, aunque no suficiente, dado que la puntuación es menor a 5 (Delgado et al., 2020).

- La democracia con peor relación respecto a las actas de defunción emitidas en 2019 contra 2020 y casos de muerte por causa directa de COVID-19 es México, con una puntuación de 4.10. Esto es una brecha enorme sobre la mortalidad en México en 2020, que nos da a entender la falta de control en diagnóstico y muertes comprobadas por COVID-19 en esta nación (Andrus et al., 2020).

- Y, por último, el país que peor comportamiento tuvo de los tres en esta comparación es México, con un promedio general de 53, en segundo lugar, Brasil, y por último y mejor calificado, Rusia, con 61 (Ferreira et al., 2021).

Como puede observarse, aunque hubo mejores rubros calificados en cada país, de manera general el desempeño de estas naciones es menor que el promedio internacional, lo que ha tendido a la disminución de su calificación. Ello indica que los países están «bajando la guardia» en una pandemia que está tan pronto a concluir en unos países, y tan lejos en otros (Nicola et al., 2020). Para finalizar, queremos hacer hincapié en la necesidad de realizar más análisis de los datos arrojados, con el objetivo de relacionar de manera individual el resultado de cada variable en cada nación con la variación en el PIB, con mayores momentos de corte y dejando la puerta abierta a una modificación de nuestro sistema de puntuación (Setiati y Azwar, 2020). 
Tabla 4. Variables usadas para el SCORE-CoV-2, su significado y la puntuación promedio de cada variable, en Brasil, México y Rusia

\begin{tabular}{|c|c|c|c|c|}
\hline Variable & Significado & $\begin{array}{l}\text { Puntuación } \\
\text { promedio } \\
\text { en Brasil }\end{array}$ & $\begin{array}{l}\text { Puntuación } \\
\text { promedio } \\
\text { en México }\end{array}$ & $\begin{array}{l}\text { Puntuación } \\
\text { promedio } \\
\text { en Rusia }\end{array}$ \\
\hline $\begin{array}{l}\text { Total de casos por } \\
\text { millón de habitantes }\end{array}$ & $\begin{array}{l}\text { Incapacidad del gobierno } \\
\text { de establecer medidas } \\
\text { eficientes de cuidado e } \\
\text { higiene }\end{array}$ & 7.31 & 9.23 & 8.76 \\
\hline $\begin{array}{l}\text { Total de muertes por } \\
\text { millón de habitantes }\end{array}$ & $\begin{array}{l}\text { Falta de insumos, camas } \\
\text { y características de la } \\
\text { población }\end{array}$ & 6.60 & 6.42 & 8.78 \\
\hline Mortalidad & $\begin{array}{l}\text { Deficiencia general en } \\
\text { salud, falta de insumos, } \\
\text { camas, características } \\
\text { del paciente }\end{array}$ & 9.34 & 7.68 & 6.24 \\
\hline $\begin{array}{l}\text { Hospitalizaciones } \\
\text { por millón de } \\
\text { habitantes }\end{array}$ & $\begin{array}{l}\text { Capacidad del sistema } \\
\text { de salud en el país }\end{array}$ & 8.33 & 5.70 & 5.67 \\
\hline $\begin{array}{l}\text { Total de pruebas por } \\
1000 \text { habitantes }\end{array}$ & $\begin{array}{l}\text { Capacidad de tamizaje } \\
\text { del gobierno }\end{array}$ & 1.66 & 1.73 & 5.24 \\
\hline $\begin{array}{l}\text { Vacunas por } \\
100 \text { habitantes }\end{array}$ & $\begin{array}{l}\text { Eficiencia en compra } \\
\text { de vacunas, logística de } \\
\text { vacunación }\end{array}$ & 0.54 & 0.26 & 0.49 \\
\hline Índice de rigor & $\begin{array}{l}\text { Conocimiento y políticas } \\
\text { gubernamentales para } \\
\text { afrontar la pandemia de } \\
\text { COVID-19 }\end{array}$ & 3.34 & 4.76 & 3.38 \\
\hline $\begin{array}{l}\text { Exceso de } \\
\text { mortalidad }\end{array}$ & $\begin{array}{l}\text { Deficiencia y falta de } \\
\text { control de muertes por } \\
\text { COVID-19 }\end{array}$ & 8.78 & 4.10 & 7.22 \\
\hline $\begin{array}{l}\text { Puntuación } \\
\text { promedio final }\end{array}$ & & 57.33 & 53 & 61.33 \\
\hline
\end{tabular}

Fuentes: Nicola et al. (2020) y Setiati y Azwar (2020). 


\section{Referencias bibliográficas}

Açikgöz, Ö. y Günay, A. (2020). «The early impact of the Covid-19 pandemic on the global and Turkish economy». Turkish Journal of Medical Sciences, 50 (SI-1), 520-526.

Andrus, J., Evans, T., Santos, J., Guzman, M., Rosenthal, P., Toscano, C., Valenzuela, M.

T., Siqueira, M., Etienne, C. y Breman, J. (2020). «Perspectives on Battling COVID-19 in Countries of Latin America and the Caribbean». The American Journal of Tropical Medicine and Hygiene, 103 (2), 593-596. https://doi.org/10.4269/ajtmh.20-0571

Aziz, N., Othman, J., Lugova, H. y Suleiman, A. (2020). «Malaysia's approach in handling COVID-19 onslaught: Report on the Movement Control Order (MCO) and targeted screening to reduce community infection rate and impact on public health and economy». Journal of Infection and Public Health, 13 (12), 1823-1829.

Banco Mundial. (8 de junio de 2020). «La COVID-19 (coronavirus) hunde a la economía mundial en la peor recesión desde la Segunda Guerra Mundial» (comunicado de prensa). https://www.bancomundial.org/es/news/press-release/2020/06/08/ covid-19-to-plunge-global-economy-into-worst-recession-since-world-war-ii

Caicedo, Y., Rebellón, D., Peñaloza, M., Cortés, H. y Méndez, Y. (2020). «Effective Reproductive Number estimation for initial stage of COVID-19 pandemic in Latin American Countries». International Journal of Infectious Diseases, 95, 316-318.

Cavallo, J. y Forman, H. (2020). «The Economic Impact of the COVID-19 Pandemic on Radiology Practices». Radiology, 296 (3), E141-E144.

Centers for Disease Control and Prevention. (2021). «Masks. Guidance for Unvaccinated People». CDC. Recuperado el 14 de marzo de 2021 de: https://www.cdc. gov/coronavirus/2019-ncov/prevent-getting-sick/diy-cloth-face-coverings.html Cepal-OPS. (2020). Salud y economía: una convergencia necesaria para enfrentar el COVID-19 y retomar la senda hacia el desarrollo sostenible en América Latina y el Caribe (pp. 1-27). OPS-Naciones Unidas.

«Coronavirus en Rusia hoy 4 septiembre: 1.015 .110 casos de Covid-19 en el país ruso». (4 de agosto de 2020). El Plural. Recuperado el 15 de marzo de 2021 de: https://www.elplural.com/sociedad/rusia-manda-80-repatriados-rusos-wuhansiberia_232654102

Delgado, D., Wyss, F., Perez, G., Sosa, A., Ponte, C., Mendoza, I. y Baranchuk, A. (2020). «Personal Safety during the COVID-19 Pandemic: Realities and Perspectives of Healthcare Workers in Latin America». International Journal of Environmental Research and Public Health, 17 (8). https://doi.org/10.3390/ijerph17082798

«Desarrolla Rusia tres fármacos contra la pandemia». (31 de marzo de 2020). La Jornada. Recuperado el 14 de marzo de 2021 de: https://www.jornada.com.mx/ ultimas/ciencias/2020/03/31/desarrolla-rusia-tres-farmacos-contra-la-pandemia4368.html 
Ferrer, R. (2020). «Pandemia por COVID-19: el mayor reto de la historia del intensivismo». Medicina Intensiva, 44 (6), 323-324. Recuperado el 14 de marzo de 2021 de: https://www.clinicalkey.es/\#!/content/journal/1-s2.0-S2173572720301272

Ferreira, C., Bonvehi, P., Torre, J. de la, Sáenz, K. y Condino, A. (2021). «Algorithms for testing COVID-19 focused on use of RT-PCR and high-affinity serological testing: A consensus statement from a panel of Latin American experts». International Journal of Infectious Diseases, 103, 260-267. https://doi.org/10.1016/j.ijid.2020.11.173

Fondo Monetario Internacional. (2021). World Economic Outlook Database (Base de datos del panorama de la economía mundial). Recuperado el 4 de abril de 2021 de: https://www.imf.org/en/Publications/WEO/weo-database/2021/April

Gobierno de México. (2021). Capacitación. Recuperado el 15 de marzo de 2021 de: https://coronavirus.gob.mx/capacitacion/

Gobierno de México, Secretaría de Salud. (2021). Versión estenográfica. Conferencia de prensa. Informe diario sobre coronavirus COVID-19 en México. Recuperado el 15 de marzo de 2021 de: https://www.gob.mx/salud/prensa/version-estenografica-conferencia-de-prensa-informe-diario-sobre-coronavirus-covid-19-enmexico-265289?idiom=es

Han, E., Tan, M., Turk, E., Sridhar, D., Leung, G. y Shibuya, K. et al. (2020). «Lessons learnt from easing COVID-19 restrictions: an analysis of countries and regions in Asia Pacific and Europe». The Lancet, 396 (10261), 1525-1534. https://doi. org/10.1016/s0140-6736(20)32007-9

Ibarra, I., Cárdenas, J., Ruiz, R. y Salazar, R. (2020). «Mexico and the COVID-19 Response». Disaster Medicine and Public Health Preparedness, 14(4), e17-e18.

Islam, K. e Iqbal, J. (2020). «An Update on Molecular Diagnostics for COVID-19». Frontiers in Cellular and Infection Microbiology, 10. https://doi.org/10.3389/fcimb.2020.560616

Khan, M., Adil, S., Adil, S., Alkhathlan, H., Tahir, M., Saif, S. y Khan, M. (2020). «COVID-19: A Global Challenge with Old History, Epidemiology and Progress So Far». Molecules, 26 (1), 39.

Li, Y., Chi, W., Su, J., Ferrall, L., Hung, C. y Wu, T. (2020). «Coronavirus vaccine development: from SARS and MERS to COVID-19». Journal of Biomedical Science, 27 (1), 104.

Logunov, D., Dolzhikova, I., Zubkova, O., Tukhvatulin, A., Shcheblyakov, D., Dzharullaeva, A. et al. (2020). "Safety and immunogenicity of an rAd26 and rAd5 vector-based heterologous prime-boost COVID-19 vaccine in two formulations: two open, non-randomised phase 1/2 studies from Russia». The Lancet, 396 (10255), 887-897. https://doi.org/10.1016/S0140-6736(20)31866-3

Medeiros de Figueiredo, A., Daponte, A., Moreira Marculino de Figueiredo, D., Gil-García, E. y Kalache, A. (2020). «Letalidad del COVID-19: ausencia de patrón epidemiológico». Gaceta Sanitaria, 1855, 3. https://doi.org/10.1016/j.gaceta.2020.04.001 
Nicola, M., Alsafi, Z., Sohrabi, C., Kerwan, A., Al-Jabir, A., Iosifidis, C., Agha, M., Agha, R. (2020). "The socio-economic implications of the coronavirus pandemic (COVID-19): A review». International Journal of Surgery, 78, 185-193. https://10. 1016/j.ijsu.2020.04.018

Organización Mundial de la Salud, OMS. (2020). «Consejos para la población sobre el nuevo coronavirus (2019-nCoV): cuándo y cómo usar mascarilla». OMS. Recuperado el 14 de marzo de 2021 de: https://www.who.int/es/emergencies/diseases/ novel-coronavirus-2019/advice-for-public/when-and-how-to-use-masks

Our World in Data. (2021). Coronavirus (COVID-19) Cases - Statistics and Research (base de datos). Recuperado el 15 de marzo de 2021 de: https://ourworldindata. org/covid-cases?country= OWID_WRL

Pardhan, S. y Drydakis, N. (2020). «Associating the Change in New COVID-19 Cases to GDP per Capita in 38 European Countries in the First Wave of the Pandemic». Front Public Health, 8 (1). https://dx.doi.org/10.3389\%2Ffpubh.2020.582140

Ribeiro, V., Telles, J. y Tuon, F. (2020). «Arboviral diseases and COVID-19 in Brazil: Concerns regarding climatic, sanitation, and endemic scenario». Journal of Medical Virology, 92 (11), 2390-2391.

Rodriguez-Morales, A., Gallego, V., Escalera, J., Méndez, C., Zambrano, L., Franco , C. et al. (2020). «COVID-19 in Latin America: The Implications of the First Confirmed case in Brazil». Travel Medicine and Infectious Disease, 35. https://doi.org/10.1016/j. tmaid.2020.101613

Rothan, H. y Byrareddy, S. (2020). «The epidemiology and pathogenesis of coronavirus disease (COVID-19) outbreak». Journal of Autoimmunity, 109. https://doi. org/10.1016/j.jaut.2020.102433

«Rusia superó los 4 millones de casos de coronavirus». (10 de febrero de 2021). INFOBAE. Recuperado el 14 de marzo de 2021 de: https://www.infobae.com/america/mundo/2021/02/10/rusia-supero-los-4-millones-de-casos-de-coronavirus/

Secretaría de Salud. Sistema de Información de la Red IRAG. (s/f). Ocupación de camas en hospitalización general 2021-03-01. Recuperado el 15 de marzo de 2021 de: https://www.gits.igg.unam.mx/red-irag-dashboard/reviewHome

Setiati, S. y Azwar, M. (2020). «Dilemma of Prioritising Health and the Economy During COVID-19 Pandemic in Indonesia». Acta Médica Indonesiana, 52 (3), 196-198.

Shrestha, N., Shad, M., Ulvi, O., Khan, M., Karamehic, A., Nguyen, U., et al. (2020). «The impact of COVID-19 on globalization». One Health, 11. https://doi.org/10.1016/j. onehlt.2020.100180

Universidad Nacional Autónoma de México, UNAM. (2020). Rusia y el Coronavirus. Recuperado el 13 de marzo de 2021 de: https://unamglobal.unam.mx/rusia-y-elcoronavirus/ 
V'kovski, P., Kratzel, A., Steiner, S., Stalder, H., y Thiel, V. (2021). «Coronavirus biology and replication: implications for SARS-CoV-2». Nature reviews. Microbiology, 19 (3), 155-170.

Wouters, O., Shadlen, K., Salcher-Konrad, M., Pollard, A., Larson, H., Teerawattananon, Y. y Jit, M. (2021). «Challenges in ensuring global access to COVID-19 vaccines: production, affordability, allocation, and deployment». The Lancet, 397 (10278), 1023-1034. https://doi.org/10.1016/s0140-6736(21)00306-8

Zhao, J., Zhao, S., Ou, J., Zhang, J., Lan, W., Guan, W., Wu, X., Yan, Y., Zhao, W., Wu, J., Chodosh, J. y Zhang, Q. (2020). «COVID-19: Coronavirus Vaccine Development Updates». Frontiers in Immunology, 11. https://doi.org/10.3389/ fimmu.2020.602256 


\section{Sobre los autores}

Jareth Lassard Rosenthal es médico cirujano y maestro en Dirección de Instituciones de Salud con Especialidad en Bienestar y Salud Corporativa, por la Universidad Anáhuac México, es voluntario y traductor de la ONU, TED y Coursera. Cuenta con especializaciones en Salud Pública y Epidemiología por la Universidad Johns Hopkins y el Imperial College London, además de varios diplomados en Educación financiera. Ha publicado diversos artículos referentes a especialidades psiquiátricas, odontológicas y oncológicas. Es colaborador en el periódico Ruiz-Healy Times y profesor anexo en el programa de especialización médica del Colegio Indoamericano. Ha trabajado en el Hospital Ángeles Mocel, donde fue jefe de médicos internos de pregrado, en instituciones de la Secretaría de Salud, en la red de colegios Semper Altius y en agencias de cobranza extrajudicial. Actualmente colabora en el Instituto Cumbres Bosques.

jarethlr@gmail.com

https://orcid.org/0000-0002-1804-7902

Carlos Alonso Medina Núñez es médico cirujano egresado de la Universidad Anáhuac México, campus Norte, actualmente cursa la maestría en Dirección de Instituciones de Salud. Labora en el CEAPS Tlazala de Fabela, del ISEM. Certificado por Goldman Sachs como analista técnico de instrumentos bursátiles. Tiene un podcast de finanzas y temas de salud titulado Docrastination, así como un canal de YouTube dedicado a la divulgación médica, llamado Docalonsito.

heyquebien@gmail.com

https://orcid.org/0000-0003-4402-5122

Joaquín Palmero Picazo es médico cirujano egresado de la Universidad Anáhuac, generación 2020, y miembro de la tercera generación del programa de Liderazgo en Medicina ALPHA. Es autor de varias publicaciones científicas en revistas indexadas y de prestigio, así como de un libro por la Editorial Académica Española sobre temas vanguardistas y de alto interés en el campo de ciencias de la salud. Tiene experiencia en asistencia médica de entidades públicas y privadas, especialmente en el área de atención de primer contacto. Fue premiado cuatro años consecutivos durante la licenciatura con el premio de Excelencia Académica en grado de Sobresaliente. Ha participado en congresos, concursos de carteles, competencias académicas, talleres, sesiones clínicas y es apasionado en la participación de brigadas médicas de asistencia social y de la investigación científica. Fue jefe de Médicos Internos de la Sociedad Beneficencia Española, en San Luis Potosí, y fue miembro del programa 
Acción Social Universidad Anáhuac. Desde 2019 es miembro activo y enlace de la Sociedad Mexicana de Estudiantes en Cardiología, SMEC.

joaquin.palmero@anahuac.mx https://orcid.org/0000-0002-7778-8057

Blanca Eugenia de la Parra Muñoz es médico cirujano egresada de la Universidad Anáhuac México, actualmente cursa la maestría en Dirección de Instituciones de Salud, en la misma universidad. Cuenta también con la especialización en Foundations of Global Health, avalada por la Universidad Johns Hopkins. Trabaja en la Clínica Endoplus, de endocrinología donde desempeña labores médico-administrativas.

blanca.dlpm@gmail.com

https://orcid.org/0000-0002-6972-4061

Leslye Lenia Mejía Martínez es licenciada en Derecho, egresada de la Universidad Anáhuac México, donde continúa con sus estudios de maestría en Dirección de Instituciones de Salud con especialidad en Salud y Bienestar Corporativo. Asimismo, cursa el Máster Global en Asuntos Públicos: Lobby, Diplomacia Corporativa y Análisis de Inteligencia en IMF Business School y en la Universidad de Nebrija. Es subdirectora de vinculación con órganos fiscalizadores en la Secretaría de Comunicaciones y Transportes. Se ha desarrollado profesionalmente en el ámbito público y privado, particularmente en el Instituto Mexicano del Seguro Social, en la administración y operatividad de hospitales en modalidad de asociación público-privada. Colaboró en la edición de la publicación «Prospectiva Jurídica de las Reformas Estructurales en México» de la serie: Textos Jurídicos de Actualidad de la Facultad de Derecho de la Universidad Anáhuac.

leslyemmtz@yahoo.com.mx

https://orcid.org/0000-0003-2126-6636

José Manuel Rivas Morales es médico cirujano, egresado de la Universidad Anáhuac México, y continúa sus estudios de posgrado en la maestría de Dirección de Instituciones de Salud en la misma institución. Realizó su internado de pregrado en el Hospital Central Militar en la Ciudad de México, y actualmente hace su servicio social en el Buen Samaritano I.A.P. en Malinalco, Estado de México, donde brinda apoyo médico en cuidados paliativos y en la consulta externa. Tiene experiencia clínica por rotaciones en hospitales nacionales e internacionales.

jmrivas29@gmail.com

https://orcid.org/0000-0002-3735-1256 